\title{
FRAMEWORK SEE-THINK-DO AS A TOOL FOR CROWDSOURCING SUPPORT - CASE STUDY ON CRISIS MANAGEMENT
}

\author{
R. Netek ${ }^{\mathrm{a} *}, \mathrm{~J}$. Panek ${ }^{\mathrm{b}}$ \\ a Dept. of Geoinformatics, Palacký University in Olomouc, 17.listopadu 50, 771 46, Olomouc, Czech Republic - \\ rostislav.netek@upol.cz \\ b Dept. of Development Studies, Palacký University in Olomouc, 17.listopadu 12, 771 46, Olomouc, Czech Republic - \\ jirkapanek@gmail.com
}

Commission WG VI/1

KEY WORDS: Crowdsourcing, Collaboration, Awareness, See-Think-Do, Crisis map

\begin{abstract}
:
See-Think-Do is a framework originally used as an approach focused on a service and product marketing on the Internet. Customers can be classified into three groups according to their involvement from potential users to real customers.

The article presents an idea of public involvement in community mapping in three levels: "See"-almost any user; "Think"potential contributors; and "Do"-interested users. The case study implements the See-Think-Do framework as an awareness-based approach used for The Crisis Map of the Czech Republic. It is an Ushahidi-based crowdsourcing platform for sharing spatial and multimedia information during crisis situations, e.g. disaster floods in 2013. While the current crisis projects use public mapping just at the onset of the disaster, according to See-Think-Do any user can be considered as a potential contributor even during the dormant period. The focus is put on the "See" and "Think" groups of contributors, which are currently ignored.

The objective of this paper is to summarize approaches (social networks, mass-media, emailing, gamification, ...) and tools (GIT/GIS, ICT, multimedia) for increasing the awareness about the project within the resting phase. That recruits a higher number of both active and passive users during the disaster. It allows the training in ICT, cartographical, spatial and GIS skills in a nonstressful way and the targeting on specific operators. Volunteers from the "Think" group may be used for data processing or rectification, GIS professionals from the "Do" group for data verification. The results refer that contributors with already established skills and required literacy (interface, data uploading) provide data faster and more accurate, the usability of the project increases based on users' comments.
\end{abstract}

\section{INTRODUCTION}

During the last decades, an enormous technology boom has impacted all areas of geoscience, including the Internet and social networks as a data resources. With the democratization of cartography as well as geographic information systems (GIS), new approaches have emerged, bringing social dimension into cartography and GIS. Collaborative mapping and community engagement are new trends in the development discourse that allow local communities to become part of the power structures and influence what is mapped and what is on the map. The paper introduces implementation of See-Think-Do framework into the field of crisis management. The idea is based on public involvement in community mapping intthe o three levels: "See group" - any user; "Think group " - potential contributors; and "Do group" - really interested users.

\section{COMMUNITY MAPPING}

The participation - public involvement in the geodata collection process - plays a major role in the process of gathering information. According to Panek (2015), the participation is a "method of acquisition, management and manipulation of geographic information that provides disadvantaged groups in society information and knowledge about spatial phenomena in their community" (Panek, 2015). From the perspective of public involvement, we are talking about community mapping / GIS, which is associated with the concepts of crowdsourcing or VGI (Volunteered Geographic Information). It indicates the involvement of public and professional awareness into community projects such as OpenStreetMap.

Community mapping in the field of crisis management is not an isolated activity. It encountered to a greater extent for the first time during the Haiti earthquake in 2010 , by both organized and spontaneous involvement of the public community in mapping critical situations. Based on a combination of OpenStreetMap and satellite images of the disaster was the current map of the affected area of Port-au-Prince within two days, then be used as the only evidence available e.g. by World Bank. Afterward, the explosion Fukushima nuclear power plant in 2011, Hurricane Sandy in 2012, the current events Cyclone Pam in March 2015 (Tomnod, 2015) and others examples could be mentioned. A list of humanitarian projects is administered by organizations such as Humanitarian OpenStreetMap Team (available from URL http://hotosm.org) or TomNod (Available from URL: http://www.tomnod.com/). Google activity in this area covers Google Crisis Response (available from URL: http://www.google.org/crisisresponse/resources.html). From another global tools Map Your World (Available from URL: http://mapyourworld.org/) or Crowdmap (Available from URL: https://crowdmap.com) could be mentioned as well (Panek, et al. 2014).

\footnotetext{
* Corresponding author
} 
The motivation of Google Company for involvement in similar projects could be marked as controversial. Rather than humanitarian objectives Google aims on marketing image. Google intentions are appropriately illustrated by a community platform Google Mapmaker (Available from URL: https://www.google.cz/mapmaker). It allows to report and correct errors in Google Maps by public. At first glance, it seems such as virtuous activity - incidentally similar to OSM strategy. Users maintain Google's map data updated for free, on the other hand, same users are limited to using them. Confirmation is served by Google conditions: "In the case of Google Map Maker gives Google users a free, perpetual and irrevocable license to use the content that you created for this service. It also agrees that the content can be edited, and it can be created derivative works. "

Currently, community-mined data are still considered inferior by stereotypical society, despite their undoubted potential. User involvement in the data collection process can be used as an alternative to the official and/or conventional sources. In the case of rapid onset emergencies, this data may completely replace conventional sources of information, especially concerning to the ever growing popularity of sharing content on social networks. Factor in community mapping is user awareness - your own pursuit of the engagement, but also brings a negative side of thing. Rightly criticized the lack of involvement give the general public the relevance and contribution of input content information. An integral part of similar systems is the phase of verification, those objective mechanisms for maintaining data quality (commonly used term Quality Assurance). Then the role of the public in addition to his own collection can also be seen in the verification of data. Most often the access of wiring specialist / independent verifier is observed.

The verification phase of community mapping is crucial viewed from the support crisis management. It is considered as more important than the data collection phase. Incorrectly interpreted information - based on inappropriate data - may have in case of emergencies disastrous consequences. Poorly estimated geographic or timing peak of the floods could leads in loss of life in extreme cases. The result could damage to own community. The same community that is entering a positive intention at the start of data acquisition cycle. This condition occurs a violation of the 90-9-1 rule. It says that $90 \%$ are just passive users without the active participation (constitute $1 \%$ of the content), $9 \%$ are occasional contributors, and only $1 \%$ are involved in active enthusiasts (constitute $90 \%$ of the content). The failure of described balance, usually increasing the proportion of inexperienced public, leads to increased number of data errors. In the case of improper mechanism of data control, it potentially reduce the credibility of data for critical decision-making processes. (Pinde and Jiuilin, 2011; Sui, Elwood et al. 2012).

90

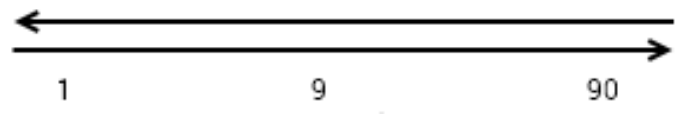

Figure $1.90 \%$ of content is made by $1 \%$ of active users

Social networks are becoming increasingly popular as one of the possible sources in community mapping. Especially younger users are accustomed to sharing any "non-standard" experiences through social networks, which thus becomes overcrowded by spatially located information. From the point of the crisis the condition brings the following benefits:

- Time character/ up-to-dateness - users shared information through social networking sites immediately after their discovery. In practice, it is the fastest type available information, often over by the mass media.

- Information character - in addition to text information is often accompanied by multimedia elements (photos, video) with higher characteristic value.

- Thematic and geographic filtering - based on the socalled hashtags (a phrase introduced by the \# symbol, for example. "\#flood") both users and rescue services can quickly filter information relevant only to a specific event. When enabled localization of the user can then limit the extra information and by territory

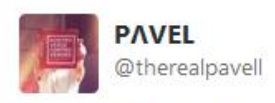

\#povodne Jiraskuv most vine.co/v/b3belqZ6Lr5 17:25, 2. čnn. 2013

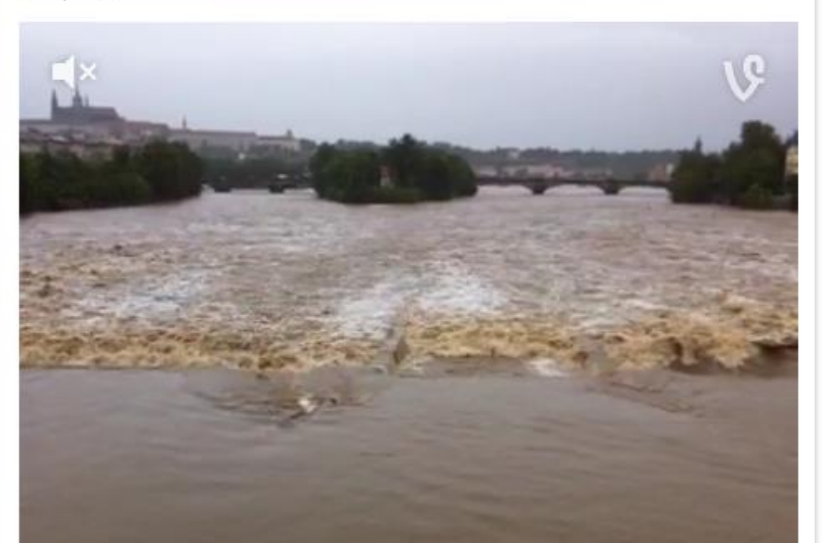

Figure 2. Twitter as a popular source of crisis information

Despite the fact that currently are available hundreds of social networks in the field of crisis management can limit their scope to the most used Facebook, Twitter, Instagram or YouTube. It is necessary to admit that current social networks become in the first phase of the crisis indispensable source of information on which many users accustomed. Social networks have become one of the fundamental pillars of information in Czech televisions during disaster floods in the Czech Republic in 2013. Based on collecting spatially localized data from both social networks and community mapping the project called Crisis Map of Czechia have been implemented (Fusková, 2014).

\section{CRISIS MAP OF CZECHIA}

Crisis Map of Czechia was a unique project of Czech Television (CT), especially by a pair of initiators: Pavlina Kvapilova (former Director of New Media in CT) and Jaroslav Valuch (The Standby Task Force Association). A public platform for sharing data in the case of emergency in the partnership with rescue services was launched in February 2013 when floods in the Czech Republic occurred. The project strategy was based on data acquisition on the principle of crowd mapping. Map data were sourced directly from public users or extracted from social 
networks. Data content was gathered by three ways. Some results have been synthesized from social network - Facebook and Twitter - under the Czech translation of tags \#crisismap or \#flood. Some records have been received by e-mail. Finally, direct entry into map applications was allowed for public.

However, only verified information (credible and relevant records verified by trained personnel) were shown in the map application. Technologically, the application was based on a platform Ushahidi. Ushahidi is an open cloud solution for the needs of the community mapping, using maps Google Maps layers. Map application displayed flood layers with report information directly from public users, including photographs and/or videos (Gisportal, 2012). In fact, any user of Crisis Map of Czechia can hold three roles during the crisis:

- Source of information - reporting original information

- Verification - verify the truthfulness

- Consumer of information - user in the affected area with an aim to obtaining relevant information

The principle of Crisis Map was based on the activation with crisis onset. Within dormant phase the application was unavailable. Crisis Map was activated only once, during a flood in 2013. It was visited by 378,000 users and received 2,798 reports, 4,500 posts from Facebook and 9,000 tweets during the ten-day activation. The map contained 1880 verified reports (Brychtová, A., V. Paszto et al., 2013). The most people used crisis map for uploading photos and information about the current state of local rivers. According to Gisportal (2012), "Crisis Map does not pretend to replace the rescue systems and spontaneously coordinate aid in the affected areas. But on the contrary, Crisis map should be a complement to a wellfunctioning system." Based on growing influence of mobile devices, Internet availability and usage of both sharing and seeking information primarily on the Internet, the similar concept can be used as one of information resources.

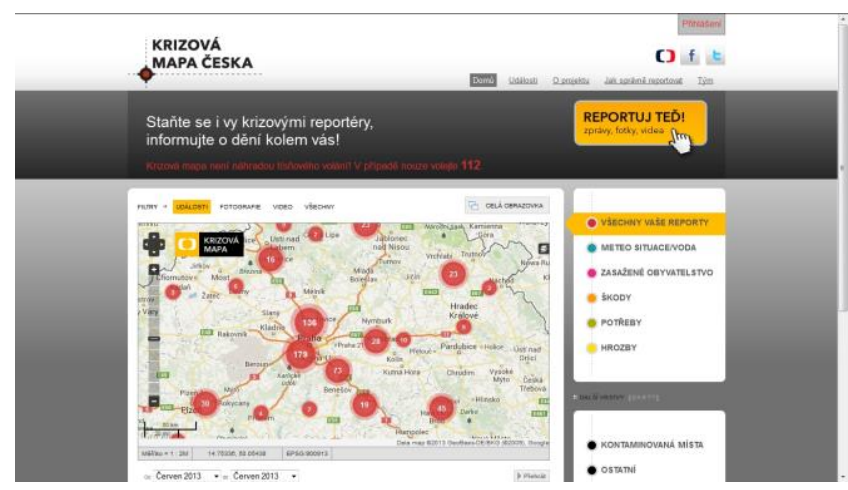

Figure 3. Crisis Map of Czechia - active status, flood 2013

\section{SEE-THINK-DO}

Avinash Kaushik, leading global web analyst (American Statistical Association, Chicago 2009), published in 2013 framework called See-Think-Do (Kaushik 2013). It is a complex concept primarily focused on content marketing typically focused on the issue of service or product marketing realized through the Internet. In simplified form, See-Think-Do could be characterized in three stages:

- See - group of potential users, in its current state they do not show interest in the product. According to Kaushik (2013), there are various violent and attractive forms (thematic blogs or social networks often without obvious requirements for a product, newsletter) to build awareness about the product or brand

- $\quad$ Think - a group of people who considering to buy a product. They are looking for product information, trying to find out purchasing options, etc. According to Kaushik, it is appropriate to prevent a premium thematic content (video tutorials, ebook)

- Do - classic customer with a particular focus on the product

Kaushik (2013) presented the framework as a pure marketing tool, he comes with the idea that any user can be considered as a potential customer. From a marketing perspective, based on a suitably chosen method for each group, we could address and communicate with potential users on a high level of efficiency. The primarily orientation to the group "See" and "Think" which are otherwise completely ignored or straight dismissed, is an innovative by the See-Think-Do approach.

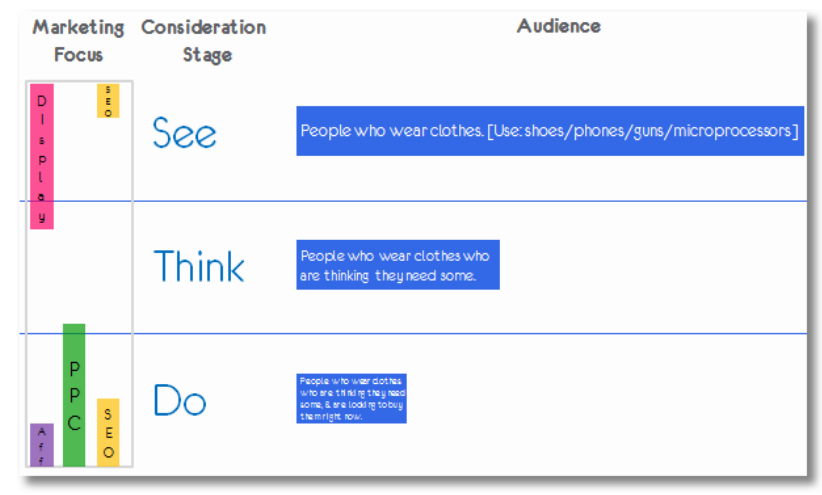

Figure 4. See-Think-Do approach, according to Kaushik (2013)

From the perspective of GIS community, mentioned principles could be fully applied in the field of crisis management. For example any crisis integrated results from social networks (see above) or VGI projects. The principle of Crisis Map of Czechia could be mentioned as the model situation. Content strategy for latent state/standby phase is possible to characterize by three groups:

- $\quad$ See - any Internet user in standard condition with no obvious affiliation to cross the map. In the first phase, it is essential that the user (in the case of emergencies) knew that the application exists. It offers to build awareness about the project / brand in the form of media, social networks, etc. In this case, it is necessary to filter out people with low IT literacy.

- Think - a group of potential users, in the standard state with an indirect relationship to the Crisis map, usually with higher IT literacy. As an indirect relationship can be defined thematic (interests in related fields such as Internet applications, GIS, mapping; typical representative student of Geoinformatics), social (volunteer/humanitarian organizations, community projects; typical representative: contributors to OpenStreetMap project) or geographic (place with a higher probability of a crisis-frequently flooded areas, ammunition dumps, localization near nuclear plants etc.) binding to a project. Considering a certain probability of involvement it is appropriate to inform the user about 
the principles of application and its services. It is awaited to take emphasis on the positive motivation of "think group" by a trainee, model situations, nonbinding tests of applications, competitions, etc. Motivational principle (scoring contest) use e.g. Old Maps Online project (available from URL http://www.oldmapsonline.org), where both volunteers from general public and experts help to georeference collections of maps.

- Do - the user with a particular focus on the crisis map directly or actively involved in the project. The need to pass as much relevant information in the form of tutorials, manuals, training videos, etc.

In the case of using the See-Think-Do framework for participatory methods, any Czech user can be considered as a potentially active user of Crisis map. Kaushik comes with the allegation that real customer groups (the group called "Do") generate only $2 \%$ conversion ratio (Kaushik, 2013) even the greatest financial resources are inserted into that. It is clear that the potential of groups "See" and "Think" is several times higher, compared to the group "Do". Jakoubek (2009) for similar group distribution use names: occasional, regular and high-end users.

The importance of a user-centered approach to all groups can be divided into two levels. In the first place, it is obviously a significant increase in awareness of the project. It recruits a higher number of active and passive users during emergencies (= active state of the application). When methods are suitably selected, it generates more relevant information. It should be noted that the thus obtained information from public sources is an invaluable resource for rescue services, especially in terms of time, but also for the public itself in the affected area.

Based on the applied approach of each group you can choose the strategy of own project management and prediction of user roles. In acute cases, it is a possible to immediate target on specific requirements for specific users and not only devise a strategy - certified volunteers from "Think group" can be used for data processing or orthorectification, experienced GIS professionals from the "Do group" for data verification, etc.

\section{SUMMARY}

Information and data obtained by the methods of community mapping can serve as an alternative to conventional sources of information. The verification process is a crucial phase. Especially the potential of social networks as quickly as possible information sources cannot be ignore. The author comes up with the idea of an application framework See-ThinkDo, as public involvement in community mapping in three levels. Crisis Map of Czechia comes with an innovative approach to custom activation maps at the onset of the crisis. A fundamental role is played by the users themselves, the data is extracted in the map on the principle of community mapping. Users are the own source of information as well as a tool of verification this information.

\section{ACKNOWLEDGEMENTS}

This paper was supported by projects of Operational Program Education for Competitiveness - European Social Fund (projects CZ.1.07/2.3.00/20.0170), of the Ministry of
Education, Youth and Sports of the Czech Republic and the student project IGA_PrF_2016_008 of the Palacký University.

\section{REFERENCES}

Brychtová, A., V. Paszto et al., 2013. Web-design evaluation of the Crisis Map of the Czech Republic using eye-tracking. In: 13th International Multidisciplinary Scientific GeoConference SGEM, Vol. 1, Sofia, Bulgaria, pp. 1065-1072.

Fusková, D., 2014. Geoinformace v prostředí sociálních sítí, Univerzita Palackého v Olomouci, Diploma thesis, 68 p.

Chicago, A. S. A., 2009. American Statistical Association 2009 Statistical Advocate of the Year Award Ceremony. http://www.chicagoasa.org/Workshops/e051509.htm (15.8.2015).

Gisportal, 2012. Krizová mapa Česka. http://www.gisportal.cz/2012/02/krizova-mapa-ceska/ (15.4.2016).

Jakoubek, K., 2009. Návrh použitelného uživatelského rozhraní webového geografického informačního systému. Univerzita Pardubice, Diploma thesis, $67 \mathrm{p}$.

Kaushik, A., 2013. See-Think-Do Content Marketing Business Framweork http://www.kaushik.net/avinash/see-think-docontent-marketing-measurement-business-framework/. (3.3.2015).

Nétek, R., M. Balun, 2014. WebGIS Solution for Crisis Management Support - Case Study of Olomouc Municipality. Lecture Notes in Computer Science 8580: 9.

Panek, J., 2015. ARAMANI - Decision-Support Tool for Selecting Optimal Participatory Mapping Method. The Cartographic Journal, 52(2), pp 107-113.

Panek, J. et al., 2014. GeoParticipace. Olomouc, Univerzita Palackého v Olomouci, 76 p.

Pinde, F. and S. Jiuilin, 2011. Web GIS: Principles and Applications, Esri Press. 312 p.

Sui, D. Z., S. Elwood and M. F. Goodchild, 2012. Crowdsourcing Geographic Knowledge: Volunteered Geographic Information (VGI) in Theory and Practice. New York, Springer. 396 p.

Tomnod, 2015. Tomnod. http://www.tomnod.com/ (15.3.2015). 